\title{
PRALLES PROGRAMM
}

\section{Liebe Leserin, lieber Leser,}

ich weiß nicht, wie es Ihnen geht, aber mir kommt es so vor, als sei dieses Jahr wie im Flug vorübergezogen. Es war vollgepackt mit tollen Themen für die MTZ und ihre Schwestern, interessanten Fachgesprächen und attraktiven Tagungen. In einem für Verlage nicht einfachen Jahr ist es uns zudem gelungen, die ATZ/MTZGruppe nicht nur auf Kurs zu halten, sondern - nicht zuletzt mit Springer für Professionals - auch die Weichen für eine prosperierende Zukunft zu stellen. Grund genug, Ihnen an dieser Stelle für Ihre Treue zu unseren Heften zu danken! Wir hoffen, Sie auch in 2013 wieder mit spannenden Themen fesseln zu können.

Auch im Tagungssektor ist der Rucksack 2013 wieder prall gefüllt. Bereits Ende Januar eröffnet „Der Antrieb von Morgen“ in Wolfsburg die Saison. Mitte Februar spannt das Stuttgarter Symposium wieder den Bogen über Automobil- und Motorentechnik. Frühjahr und Sommer sind die Zeit der ATZ-Fachtagungen „Werkstoffe im Automobilbau“ in Stuttgart, „chassis. tech plus“ in München und „Automotive Acoustics Conference“ in Zürich, die wir Ihnen als Ergänzung Ihres Kerngebietes ebenfalls ans Herz legen wollen. Und im Herbst geht es dann Schlag auf Schlag: Die 15. „Virtual Powertrain Creation“ führt im September die Simulationsexperten ebenso zusammen wie die „Ladungswechsel im Verbrennungsmotor" die Motorspezialisten im Oktober. Es folgt die „Heavy Duty“ im November, die Tagung für all jene Entwickler, die selbst einen V12-Nfz-Motor als „niedlich“ bezeichnen. Den krönenden Abschluss bildet dann die „Reibungsminimierung im Antriebsstrang" Ende November.
Sie sehen, wir haben nicht zu viel versprochen - das Jahr 2013 ist dichtgepackt mit interessanten Fachtagungen. In Kombination mit unseren Fachmedien ATZ, MTZ, ATZelektronik, ATZoffhighway, MTZindustrial und Lightweight Design hoffen wir so, Sie umfassend informieren und bei Ihrem persönlichen Networking unterstützen zu können. Es würde uns freuen, Sie bei einer dieser Veranstaltungen begrüßen und mit Ihnen diskutieren zu dürfen. In diesem Sinne wünscht Ihnen die Redaktion ein erfolgreiches und vor allem gesundes Jahr 2013.

Herzlichst, Ihr

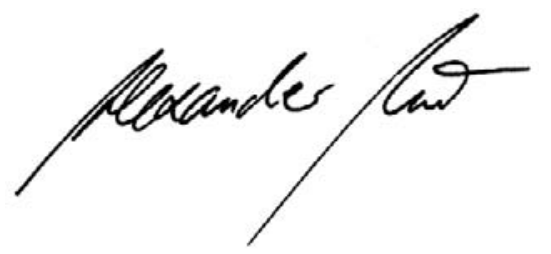

DR. ALEXANDER HEINTZEL, Chefredakteur Wiesbaden, 4. Dezember 2012

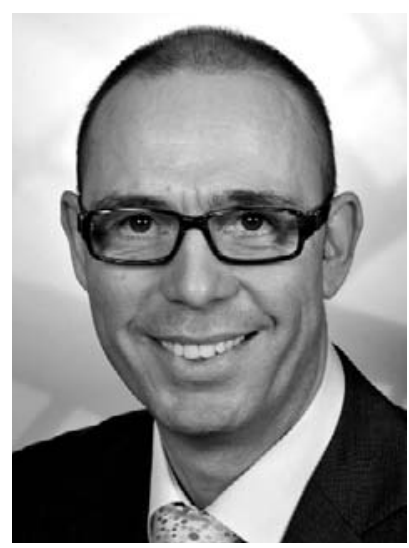

\section{Sound of Silence}

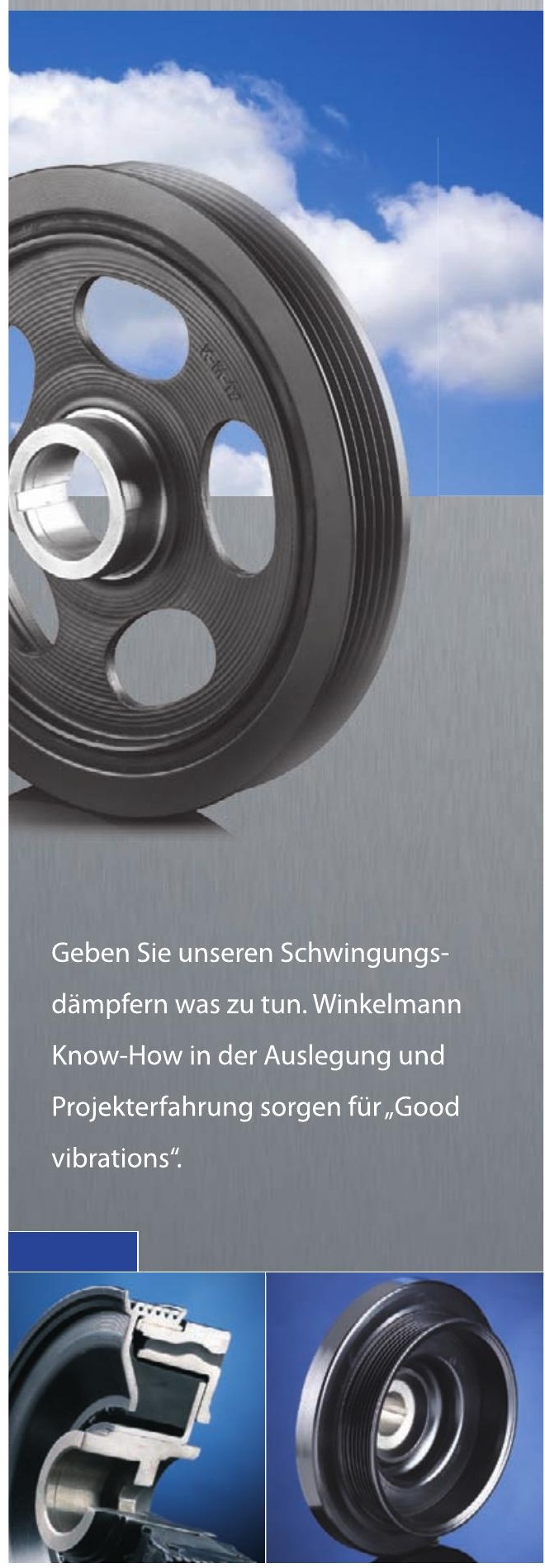

Winkelmann Powertrain Components 